\title{
De la higiene mental, solidaridad y resistencia obrera al uso hegemónico de la psicología en Santiago de Chile, 1920-1950
}

Resumen: El presente trabajo se enfoca en la recepción que la clase trabajadora organizada de Santiago de Chile hizo de los postulados de las disciplinas psicológicas, especíicamente de la higiene mental. Enfocados en una reconstrucción histórica, en la que se toma a la prensa obrera anarquista comunista y socialista de mediados del siglo XX, se evidencia una preocupación sobre las consecuencias mentales del capitalismo en la clase obrera. Se señala con este recorrido una ruta alterna a la historia de los saberes psicológicos con lo que se muestra la agencia de la clase popular metropolitana en Chile. Palabras clave: historia de la psicología, clase obrera, prensa obrera, higiene mental.

\section{From mental hygiene, solidarity and worker resistance to the hegemonic use of psychology in Santiago de Chile, 1920-1950}

Abstract: This paper focuses on the organized working class of Santiago de Chile's reception of the postulates of the psychological disciplines, specifically of mental hygiene. Focused on a historical reconstruction that takes on the communist, socialist and anarchist working-class press of the mid-twentieth century, the paper brings to light a concern about the mental consequences of capitalism on the working class. In this way, an alternative route to the history of psychological knowledge opens up, showing the agency of the popular metropolitan class in Chile.

Keywords: history of psychology, working class, workers press, mental hygiene.

\section{Da higiene mental, solidariedade e resistência dos trabalhadores ao uso hegemônico da psico- logia em Santiago do Chile, 1920-1950}

Resumo: Este trabalho enfoca a recepção que a classe trabalhadora organizada de Santiago do Chile fez dos postulados das disciplinas psicológicas, especificamente da higiene mental. Voltado a uma reconstrução histórica, na qual se toma a imprensa anarquista, comunista e socialista de meados do século XX, evidencia a preocupação com as consequências mentais do capitalismo para a classe trabalhadora. Assinala-se, com este percurso uma via alternativa para a história dos saberes psicológicos, mostrando-se a agência da classe trabalhadora metropolitana no Chile.

Palavras-chave: história da psicologia, classe trabalhadora, imprensa de trabalhadores, higiene mental.

Cómo citar este artículo: Mariano Ruperthuz Honorato, "De la higiene mental, solidaridad y resistencia obrera al uso hegemónico de la psicología en Santiago de Chile, 1920-1950”, Trashumante. Revista Americana de Historia Socia/ 18 [2021]: 190-211.

DOI: 10.17533/udea.trahs.n18a09

\section{Fecha de recepción: 27 de abril de 2020}

Fecha de aprobación: 8 de octubre de 2020

Mariano Ruperthuz Honorato: Doctor en Psicología por la Universidad de Chile y doctor en Historia por la Universidad de Santiago de Chile. Profesor Investigador en la Universidad Andrés Bello y la Universidad de Santiago de Chile. Investigador Visitante del Programa de Pós-Graduação em História das Ciências e da Saúde da Casa de Oswaldo Cruz [COC- Fiocruz, Río de Janeiro]. ORCID: 0000-0002-4924-4554.

Correo electrónico: mariano.ruperthuz@unab.cl 


\section{De la higiene mental, solidaridad y resistencia obrera al uso hegemónico de la psicología en Santiago de Chile, 1920-1950*}

Mariano Ruperthuz Honorato

\section{Introducción}

U na revisión sistemática de la prensa obrera comunista, socialista y anarquista publicada en Santiago de Chile entre 1920 y finales de 1950 —enmarcadas en una investigación sobre el desarrollo del Estado benefactor en Chile y la psicología en el sentido amplio- mostró, de manera llamativa, la inclusión de referencias propias de las disciplinas psicológicas que se relacionaban con una preocupación por el estado mental de sus seguidores producto de las condiciones de vida asociadas a la vida metropolitana y al capitalismo como sistema económico. En este sentido, es posible advertir que varios de los sufrimientos, aspiraciones, reivindicaciones y proyectos de estos seres humanos, junto a sus respectivos proyectos políticos, se nutrieron de las ideas, teorías y técnicas de la psicología, la psiquiatría y el psicoanálisis en una clave higiénico mental que buscaba prevenir la aparición de trastornos psíquicos. Como lo han demostrado algunos historiadores chilenos, por ejemplo, María Angélica Illanes Oliva, la clase trabajadora nacional fundó desde el último cuarto del siglo XIX y con mayor fuerza desde comienzos del siglo XX —ligado a los fenómenos propios de la llamada "cuestión social"— organizaciones solidarias de socorro mutuo para enfrentar la inseguridad vital y protegerse de manera autónoma y mutualista. ${ }^{1}$ Se trataría del nacimiento de la llamada salud social "basada en el humanismo popular y la organización solidaria y como

* Este artículo forma parte del Proyecto AIND-FONDECYT Regular N ${ }^{\circ} 1190226$ "El rol de la higiene mental en la definición del modelo de asistencia psiquiátrica en Chile (1917-1954)", Escuela de Psicología, sede Santiago, Universidad Andrés Bello; y del Proyecto Anillos de CONICYT (SOC-1110): 2013-2015 "Iluminando un dilema educacional en la complejidad de un mundo multicultural. Fortalecimiento de la formación en Ética e Interculturalidad en estudiantes universitarios (as) y profesionales", Escuela de Psicología, Universidad de Santiago de Chile.

1. María Angélica Illanes Oliva, "En el nombre del Pueblo, del Estado y de la Ciencia (...)". Historia de la salud pública. Chile, 1880 / 1973. (Hacia una historia social del siglo XX) (Santiago de Chile: Ministerio de Salud, 2010) 15-34. 
una alternativa expresamente contrapuesta a la caridad, a quien estaba entonces contratado el cuidado del pueblo enfermo, hecho objeto de expiación social".2

El movimiento obrero chileno, principalmente, se vio impulsado desde el norte del país, donde trabajadores de centros portuarios y mineros comenzaron a organizarse en torno a las primeras mutuales, mancomunales y sindicatos. La transformación de una economía colonial hacia un sistema capitalista - con una fuerte inversión extranjera - hizo mutar al artesanado hacia una proletarización de la fuerza de trabajo. Los procesos de industrialización se acompañaron de pésimas condiciones de vida para la masa trabajadora, lo que exhibía las consecuencias de la explotación obrera y, con ello, estimulaba mayores niveles de politización e ideologización para afrontar las desventajosas condiciones de vida. Si bien la difusión de ideas liberales facilitó la organización de la Federación Obrera de Chile (FOCH) en 1910 - tal como lo plantea Miguel Fuentes — ${ }^{3}$ el posicionamiento de clase a partir del ideario marxista, socialista y anarquista consolidará el nacimiento de la clase trabajadora como un actor político sensible a ideologías reformistas y revolucionarias a partir de las lecturas de autores como Pierre Joseph Proudhon, Karl Marx, Mikahail Aleksandrovic Bakunin, Piotr Kropotkin, entre otros. ${ }^{4}$ Adicionalmente, estas agrupaciones - al menos sus cúpulas dirigenciales - también fueron receptivas a las ideas de Sigmund Freud, Iván Pavlov — con primitivos intentos de compatibilizar bajo el rótulo de freudopavlovismo - Gregorio Marañón y Santiago Ramón y Cajal, autores que fueron citados explícitamente en las publicaciones obreras.

Atacar males como el alcoholismo, educarse en materia sexual para tener un control eugenésico y neomalthusiano de la natalidad, ejercer una paternidad y maternidad responsables y, sobre todo, resistir la "hipnosis" del capital y el fascismo reflejan una resemantización de estos problemas bajo un código psicológico. La hipótesis central, entonces, indica la existencia de un proceso de discusión, apropiación y compatibilización teórica, tecnológica y especialmente política de una parte de la clase obrera organizada — reflejada en varios pasajes de la prensa obrera- de las ideas de las psicologías en la primera mitad del siglo XX en Santiago de Chile. De esta manera, buscaban alimentar sus propios proyectos políticos y resistir al uso que la organización del Estado hacía de la psicología que problematizaba exclusivamente la vida de la familia popular en términos psicopatológicos. ${ }^{5}$ En este sentido, el trabajo historiográfico ha iluminado hasta ahora las precarias condiciones de vida de la clase obrera urbana en términos de salud física. Una clase atacada por enfermedades infecciosas como el tifus exantemático, la tuberculosis

2. Illanes Oliva 36 .

3. Miguel Fuentes, "Entre el nacimiento de la clase obrera en Chile y su constitución como sujeto político. El ‘Congreso Obrero’ de 1885 y la Huelga general de 1890 como antecedentes históricos de la matanza de Santa María”, Cuadernos de Historia Marxista 1.1 (2009): 1-19.

4. Peter DeShazo, Trabajadores urbanos y sindicatos en Chile: 1902-1927 (Santiago de Chile: Centro de Investigaciones Diego Barros Arana de la Dirección de Bibliotecas, Archivos y Museos, 2007) 143.

5. Mariano Ruperthuz Honorato, Freud y los chilenos (Santiago: Pólvora Editorial, 2016) 225 y ss. 
y la viruela, que se sumaban a la desnutrición, el raquitismo y el alcoholismo que diezmaban la vida popular. ${ }^{6}$

Este trabajo se enfocará específicamente en la prensa obrera como fuente principal de información, advirtiendo, como lo afirma Mirta Lobato, que ella estuvo destinada y estructurada a los trabajadores bajo la consiga "saber es poder". Vale decir, "conocer" era la base de la capacitación del obrero - y por defecto de toda su clase social - " "para la práctica política que lo libraría de la opresión y el dominio burgués. Los periódicos gremiales tenían un sentido pedagógico y buscaban erradicar los males que introducía en las mentes y la cultura obrera el pensamiento burgués a través de los grandes diarios". " Es desafiante, bajo este marco, para los trabajos sobre la historia de los saberes psicológicos entender cómo, por qué y para qué la prensa socialista, comunista y anarquista metropolitana habrían participado activamente de un proceso de "medicalización" y "psicologización" de sus propias demandas sociales y políticas que tuvo lugar en una historia que hasta ahora en Chile era exclusiva de los sectores más acomodados y oficiales de la política y la ciencia local.

De esta manera, se busca dialogar con investigaciones que desde hace unos años han reconstruido la historia de la higiene mental en Iberoamérica - como las de Rafael Huertas, Ricardo Campos Marín, Andrés Ríos Molina, Alejandro Dagfal, Cristiana Fachinetti y Ana Teresa Venancio, Silvana Vetö, entre tantos otros- que se han enfocado mayoritariamente en una historia basada en los discursos de distintos personeros del mundo estatal y médico que buscaban prevenir la aparición de la enfermedad mental en sus respectivos espacios nacionales. ${ }^{10}$ Lo anterior, naturalmente obligaría a tener una visión crítica acerca de quiénes son los protagonistas de la historia de la ciencia psicológica, qué papel juegan en su aplicación

6. DeShazo 115-118.

7. Mirta Zaida Lobato, La prensa obrera (Buenos Aires: Edhasa, 2009) 10.

8. Nicolás Fuster Sánchez, El cuerpo como máquina. La medicalización de la fuerza de trabajo en Chile (Santiago de Chile: CEIBO Ediciones, 2013) 11-46; Michel Foucault, La vida de los hombres infames. Ensayos sobre desviación y dominación (La Plata: Altamira, 2006) 85-105.

9. Nikolas Rose, La invención del sí mismo. Poder, ética y subjetivación (Santiago de Chile: Pólvora Editorial, 2019) 185-208; Jan DeVos, Psychologisation in Times of Globalisation (Nueva York: Routledge, 2012) 15-30.

10. Rafael Huertas, "El papel de la higiene mental en los primeros intentos de transformación de la asistencia psiquiátrica en España”, Dynamis 15 (1995): 193-209; Ricardo Campos Marín, "De la higiene del aislamiento a la higiene de la libertad. La reforma de la institución manicomial en Francia (1860-1940)", Frenia. Revista de Historia de la Psiquiatría 1.1 (2001): 37-64; Andrés Ríos Molina, Cómo prevenir la locura. Psiquiatría e higiene mental en México, 1934-1950 (México: Siglo XXI Editores, 2016) 11-16; Alejandro Dagfal,"El pasaje de la higiene mental a la salud mental en la Argentina, 1920-1960. El caso de Enrique Pichon-Rivière", Trashumante. Revista Americana de Historia Social 5 (2015): 10-36, doi: 10.17533/udea.trahs.n5a02; Ana Teresa Venancio y Cristiana Facchinetti, "Historiografias: de la psiquiatría en Brasil y sus instituciones", Revista Argentina de Psiquiatría 27 (2016): 177-187; Silvana Vetö, "Higiene mental infantil y psicoanálisis en la Clínica de la Conducta, Santiago de Chile, 1936-1938", Asclepio. Revista de Historia de la Medicina y de la Ciencia 69.2 (2017): 1-17, doi: 10.3989/asclepio.2017.18. 
—pensando en los "objetos" de la asistencia mental- y los usos que hacen de ella. Por otro lado, este trabajo también toma en cuenta aquellos estudios que han señalado los diálogos que los saberes de la mente han tenido con los sectores legos, tal como lo ha mostrado las obras de Annette Mülberger, Mauro Vallejo y María José Correa. ${ }^{11}$

\section{1. ¿Quién protagoniza la historia de los saberes psicológicos? El caso de una posible higiene mental obrera}

La historia de los llamados "saberes psi” — que reúnen a la psicología, la psiquiatría y el psicoanálisis — ${ }^{12}$ entendidos como un conjunto diverso y heterogéneo de saberes que tienen al "elemento mental" como común denominador se han centrado mayoritariamente en los actores y representantes considerados "oficiales" de la ciencia. Desde esta perspectiva, cuando se habla de higiene mental se hace referencia comúnmente a la historia del movimiento transnacional en salud que buscó la prevención de la aparición de los trastornos psíquicos en la población, en vez de su solo tratamiento represivo. ${ }^{13}$ Esta cruzada médica y política reunió a un crisol de agentes inspirados, por un lado, en la experiencia del norteamericano Clifford Beers como paciente psiquiátrico, quien publicó un libro autobiográfico en 1908 en el que relataba su experiencia de internación y así sensibilizaba a buena parte del mundo médico y la sociedad civil estadounidense, y, por otro lado, las enseñanzas del médico psiquiatra marsellés Edoard Toulouse, quien buscó una reforma del asilo como única herramienta para el tratamiento de la enfermedad mental, impulsó iniciativas como el Open Door y las colonias agrícolas con los que generó nuevos dispositivos de asistencia y control social. ${ }^{14}$ Estos agentes estaban esparcidos por distintos países, entre ellos Chile, y generaron importantes movimientos reformistas a la psiquiatría manicomial, fundaron ligas de pro-higiene mental y realizaron una especie de "evangelización" de la población para que se cultivara en términos psicológicos. Es un capítulo de la emergencia e implantación del llamado psychological man, ${ }^{15}$ figura secularizada en la que el ser humano estaría habitado de una psique individual, la que debe ser cultivada desde sus primeros

11. Annette Mülberger, Los límites de la ciencia, espiritismo, hipnotismo y el estudio de los fenómenos paranormales (1850-1930) (Madrid: Consejo Superior de Investigaciones Científicas, 2016) 1-20; María José Correa y Mauro Vallejo, Cuando la hipnosis cruzó los Andes. Magnetizadores y taumaturgos entre Buenos Aires y Santiago (1880-1920) (Santiago de Chile: Pólvora Editorial, 2019) 1-30.

12. Rose 39.

13. Mathew Thomson, "Mental hygiene as an international movement", International Health Organisations and Movements, 1918-1939, ed. Paul Weindling (Cambridge: Cambridge University Press, 1995) 283-304.

14. Ricardo Campos Marín, "La psiquiatría en la ciudad. Higiene mental y asistencia psiquiátrica extramanicomial en España en la década de 1920”, Frenia. Revista de Historia de la Psiquiatría 4.1 (2004): 101-111; Rafael Huertas, Historia cultural de la psiquiatría (Madrid: Catarata, 2012) 38-45.

15. Philip Rieff, The Triumph of the Therapeutic. Uses of Faith after Freud (Wilmington: ISI Books, 2006) 7-34. 
años de vida por lo que las disciplinas humanas debían alimentarse de la psicología para llevar a cabo esa misión. ${ }^{16}$

En términos de historia global, sería imposible hablar de un solo movimiento de higiene mental uniforme - si se consideran los ejemplos de investigaciones históricas sobre la circulación de sistemas de ideas y creencias transnacionales como, por ejemplo, el marxismo y el psicoanálisis — ${ }^{17}$ se deberían integrar los filtros de origen de los agentes receptores de estas ideas, los que moldearon sin lugar a duda su apropiación local. Así, correspondería pensar en la acción de tamices como el origen social, cultural, político y científico particulares de los actores que históricamente estuvieron involucrados en la prevención de la enfermedad mental abonados a este movimiento. Sería posible afirmar analíticamente que se podrían distinguir distintos niveles de recepción de higiene mental: a) el recorrido que estas teorías tuvieron desde los centros internacionales — como era el caso de Estados Unidos y Francia - hacia la "periferia”, discutidas por los "expertos" (médicos, psiquiatras, juristas, pedagogos, visitadoras sociales, entre otros, con más o menos influencia en el Estado). Esta sería una recepción "desde arriba" en términos sociales. Y b) una recepción "desde abajo" — tal como lo afirma el historiador Gabriel Salazar- ${ }^{18}$ que aglutina las discusiones y prácticas de los llamados "no expertos", y logran darle voz y protagonismo a quienes son generalmente excluidos por la historia oficial de la ciencia psicológica. Si bien es dificil afirmar que se trataría de una lectura directa de parte de los propios obreros, ya que los diarios obreros muchas veces eran editados por las cúpulas ilustradas, sí estuvieron por fuera de los circuitos profesionales, lo que generó lecturas legas que apuntaban a las esferas simbólicas de la vida popular. Aunque la higiene mental es un objeto privilegiado en este trabajo, se busca, a su vez, entender cómo históricamente los saberes científicos circulan por distintos niveles de la sociedad. Así las obras de, por ejemplo, Álvaro Girón Sierra, Mario Lázaro y Manuel Cortés, y el ya nombrado Ricardo Campos, que enseñan cómo otros saberes como el lombrosianismo y la eugenesia también empaparon la retórica obrera. ${ }^{19}$

Estudios históricos como los de E. P. Thompson sobre la clase trabajadora en Inglaterra en el cual se enfocó en la "humilde vida" de los tejedores y en el papel de los pintores dentro de las vanguardias artísticas del siglo XX, o los trabajos de

16. Eva Illouz, La salvación del alma moderna. Terapia, emociones y la cultura de la autoayuda (Madrid: Katz Editores, 2010) 9-36.

17. Joy Damousi y Mariano Ben Plotkin, eds., The Transnational Unconscious. Essays in the History of Psychoanalysis and Transnationalism (Londres: Palgrave Macmillan, 2009) 1-16.

18. Gabriel Salazar, La historia desde abajo y desde adentro (Santiago de Chile:Taurus, 2017) 1-40.

19. Álvaro Girón, "Kropotkin between Lamarck and Darwin: the impossible synthesis", Asclepio. Revista de Historia de la Medicina y de la Ciencia 55.1 (2003): 189-213, doi: 10.3989/asclepio.2003. v55.i1.94; Mario Lázaro y Manuel Cortés, Anarquismo y lucha antialcohólica en la Guerra Civil Española (1936-1939) (Madrid: Papel Piedra, 2005) 10; Ricardo Campos Marín, Alcoholismo, medicina y sociedad en España (1876-1923) (Madrid: Consejo Superior de Investigaciones Científicas, 1997) 189-220. 
Eric Hobsbawm para mostrar la capacidad de resistencia a la producción de masas y la tecnología de repetición infinita, van en esa dirección: la de reconocer la capacidad agencial de los excluidos de la historia. ${ }^{20}$ Descentrar el lugar de quien enuncia en el campo psicológico permitirá ver la capacidad de lectura de estas ideas, las que también hablan de su cualidad epistémica para ser altamente recepcionadas por comunidades no doctas, ${ }^{21}$ las cuales experimentan un verdadero proceso de "indigenización" 22 e impulsan el desarrollo de culturas psicológicas en determinados espacios sociales. ${ }^{23}$ Todo esto ayudaría a valorar el alcance, la "generosidad" de la psicología para construir públicos, agentes, tecnologías amplias para la prevención de la enfermedad mental. Los trabajadores organizados adoptaron un tono ilustrado que se expresaba en la generación de mensajes bajo el código del progreso y la emancipación. ${ }^{24}$ Se empaparon de las vanguardias europeas en términos científicos y, como podremos ver aquí, de las ideas higienistas que circulaban en los sectores gobernantes para evangelizar a los desclasados, pero que ellos utilizarán en un tono protagónico.

Por último, las fuentes asociadas a este trabajo fueron revisadas en los archivos de la prensa obrera disponible en la Biblioteca Nacional de Chile, la cual conformaría un material crucial para acceder a las posibles representaciones psicologizadas de la higiene mental, representaciones sobre la enfermedad mental, posibles curas y promoción de la salud mental para los (as) obreros (as). ${ }^{25}$ Se incluyó la prensa obrera desde sus vertientes comunista, anarquista y socialista. Así, dentro de los periódicos revisados se encuentran: Acción Directa, Santiago, Agitación, Autonomía y solidaridad, Bandera Roja, Boletín de los Trabajadores Industriales del Mundo, El Comunista, El Despertar de los tranviarios, El Metalúrgico, El Obrero del Calzado, El Sindicalista, El Tranviario, Federación Chilena del Trabajo, Hoja Sanitaria I.W.W, La Acción Popular, La Antorcha, La Bandera Roja y Tribuna Libertaria. ${ }^{26}$ De modo general se puede afirmar

20. E. P.Thompson, La formación de la clase obrera en Inglaterra (Madrid: Capitán Swing, 2012) 27-38 y 301-348; Eric Hobsbawm, A la zaga. Decadencia y fracaso de las vanguardias del siglo XX (Barcelona: Crítica, 1999) 9-22.

21. Patricia Gherovici y Christopher Christian, eds., Psychoanalysis in the Barrios. Race, Class, and the Unconscious (Londres: Routledge, 2019) 1-18.

22. Paul Heelas y Andrew Lock, Indigenous Psychologies. The Anthropology of the Self (Londres / Nueva York: Academic Press, 1981) 3-18.

23. Sherry Turkle, Psychoanalytic Politics. Jacques Lacan and Freud's French Revolution (Nueva York: The Guilford Press, 1992) 191.

24. Eduardo DevésValdés, "La circulación de las ideas económico-sociales de Latinoamérica y el Caribe, en Asia y África ¿cómo llegaron y cómo se diseminaron? (1965-1985)”, Universum. Revista de Humanidades y Ciencias Sociales 23.2 (2008): 87-93.

25. Santiago Aránguiz Pinto, "Rusia roja de los soviets: recepción de la Revolución Rusa, del bolcheviquismo y de la cultura política en el mundo obrero revolucionario chileno (1917-1927)" (Tesis de doctorado en Historia, Pontificia Universidad Católica de Chile, 2012) 20.

26. Se debe dejar en claro que las publicaciones de los periódicos de obreros no cuentan en su mayoría con autores de sus artículos publicados y varios de ellos tampoco tienen número de página. Por esto, se omitirá el autor y se pondrá sin página (s.p.) cuando corresponda. 
que la prensa obrera consultada se caracteriza por ser de una periodicidad eventual, quincenal y semanal. Son pocas las que tuvieron una larga vida, pero dentro de las consultadas se encuentran Acción Directa (1921-1924 y con una reaparición en 1934), Tribuna Libertaria (1923-1926), La Hoja Sanitaria (1924-1927), El Despertar Tranviario (1938-1954), El Metalúrgico (1940-1941, y con una reaparición en 1953), y El Sindicalista (1933-1935). La vida de estos periódicos está directamente vinculada con la capacidad de autogestión de las organizaciones que las soportan, pero en su mayoría eran gratuitos o a cambio de un aporte voluntario. Generalmente trataban temas de la vida obrera en términos de análisis o comentarios de los pormenores del movimiento, orientaciones políticas y doctrinarias, denuncias contra la clase política y, como es atingente con este trabajo, información variada que buscaba incrementar los niveles de educación de sus lectores.

\section{Resultados}

\subsection{Los anarquistas metropolitanos, la sociedad de la muerte y la psique}

La crisis nacional de los años veinte se vio reflejada en el diagnóstico que los anarquistas tenían de la realidad social chilena. La explotación, el desempleo, el alcoholismo y las enfermedades de transcendencia social estaban a la orden del día. El pueblo inculto necesitaba de una "acción directa" sin esperar nada de parte del Estado, la Iglesia o el Ejército. La sociedad era vista como un conjunto de fuerzas asesinas, una verdadera oda a la muerte de los más débiles que superaba por mucho al instinto de conservación de los individuos. Los sentimientos, la mente - representada por el cerebro - y el cuerpo eran víctimas del castigo social que la desigualdad provocaba: "Más bien que una oda a la muerte, la sociedad actual parece una compañía de exterminio mutuo. Se mata el estómago, el corazón y el cerebro [...] Nos ahoga la miseria económica, la preocupación religiosa, la farsa autoritaria, el duelo colectivo de los campos de batalla". ${ }^{27}$

La participación de los anarquistas en la legalidad política imperante era totalmente descartada, lo mismo que las redes de poder que articulaban al Ejército, la Iglesia, la banca y los llamados a hacer crecer la patria. ${ }^{28}$ Desde su tribuna, las elites eran vistas como los verdaderos degenerados de la escena social, quienes obsesivos sufrían —en términos psicopatológicos — de una "obsesión macabra: la conservación del 'orden social', la obsesión los perderá, todo está en que sigan atracando para que el pueblo arda y estalle como pólvora". ${ }^{29}$

El análisis que se expresaba desde la pluma anarquista identificaba al desempleo ocasionado por el desarrollo industrial. Las nuevas tecnologías fabriles, si

27. "La sociedad de la muerte", Acción Directa (Santiago de Chile) primera quincena de enero de 1921: s.p.

28. "Sin trabajo", Acción Directa (Santiago de Chile) primera quincena de febrero de 1922: 7.

29. "Represión y orgía", Agitación (Santiago de Chile) 14 de junio de 1925:1. 
bien habían traído prosperidad en muchos sentidos, también habían generado una masa importante de desempleados con el pauperismo como protagonista.

La organización ácrata — como era tradicional— había promovido la labor educativa como eje central de la formación de sus adherentes. Así, por ejemplo, el "Grupo Universitario Lux", ${ }^{30}$ como su nombre lo indicaba, "proyectaban la luz" de la educación para mejorar la condición de los explotados con base en cursos de matemáticas, castellano, inglés, economía, política y dibujo industrial. De todas maneras, a este conjunto de saberes se le agregó instrucción en educación sexual con el propósito de controlar la natalidad para no ofrecerle hijos al sistema explotador:

Tengo una pregunta para ti socio, hermano mío. La arrojo como una sombra en tu alma, para conocer la profundidad -Eres joven y deseas hijo y matrimonio:-¿Eres hombre que tengas derecho a tener un hijo? ¿Eres el victorioso vencedero de ti mismo, el amo de tus sentidos, el soberano de tus virtudes? ¿O bien las bestias y la necesidad hablan en ti, en nombre de tu deseo? Quiero que tu victoria y tu libertad engendren el deseo de un hijo. Debes construir más arriba que tú mismo. Pero antes es menester que tu mismo estés construido. ${ }^{31}$

Tener un hijo implicaba, desde estas ideas, un acto racional, controlado y medido en el cual los sujetos estaban en un diálogo interior fluido y armónico consigo mismos. Las bestias interiores — representadas por los impulsos sexuales- debían ser controladas para evitar embarazos no deseados. Los niños pequeños no debían ser la carne de cañón del capitalismo, no podían los obreros pagar tan alto precio por su irresponsabilidad genésica. ${ }^{32}$

Un gesto claro que aparece a mediados de la década de los veinte en el periódico Tribuna Libertaria fue la publicación de la columna titulada "Psicología Integral". En ella, al estilo magazine, se tocaron distintos tópicos de psicología general, enseñanzas preventivas y algunas recomendaciones de autoayuda. Siempre se reforzaba la armonía entre cuerpo y alma, pero también siempre con la idea de que es el carácter el que podía - cuando era bien preparado- enarcar los riesgos que las pasiones le comportan. ${ }^{33}$ La acción preventiva implicaba que "Las personas nerviosas con tendencia a la melancolía necesitan poner en práctica un principio tásico de la higiene mental, huir de la tristeza.Y para ello deben luchar contra el ambiente pesimista, que como atmósfera pesada y obscura los rodea y abruma". ${ }^{4}$

El ambiente era modificable por lo que el determinismo podía ser dejado atrás. Los sujetos debían, entonces, "alejarse de medios en los que la neurosidad o la melancolía estuvieran presentes de manera amenazante. Un ambiente pesimista,

30. "El hogar común", Acción Directa (Santiago de Chile) segunda quincena de mayo de 1922: s.p.

31. "De Nietzche", Acción Directa (Santiago de Chile) segunda quincena de diciembre de 1922: 3.

32. "Sobre educación", Tribuna Literaria (Santiago de Chile) primera quincena de diciembre de 1923:s.p.

33. "Psicología Integral", Tribuna Literaria (Santiago de Chile) primera quincena de octubre de 1924: s.p.

34. "Psicología Integral: El ambiente pesimista", Tribuna Literaria (Santiago de Chile) 1 de noviembre de 1925: 4 . 
según esta publicación, se formaban por [...] el lenguaje, la lectura, las amistades y los espectáculos". 35 De manera solidaria con esta percepción, la infancia fue valorada como un periodo crítico de la existencia humana. Para este propósito el psicoanálisis pasó a ser una pieza dentro de este diseño social. Así, por ejemplo, el psicoanalista chileno Ramón Clarés subrayaba esta idea basado en autores tan consagrados como los psicoanalistas galos Ángelo Hesnard y Marie Bonaparte — princesa de Grecia y discípula directa de Sigmund Freud- para introducir la idea de la sexualidad infantil:

Esto es lo que ha hecho decir a María Bonaparte, al referirse a la masturbación infantil: los adultos ilustrados por los descubrimientos del psicoanálisis deberían dejar de atribuirse el monopolio de la sexualidad. El niño tiene también, una sexualidad a su medida, y a ella tiene derecho. Esta sexualidad está dentro del orden de la naturaleza y no puede considerársele un vicio excepcional. Con lo demás, en vez de hacer del onanismo del niño, y que, a su debido tiempo pudiera tratar el asunto con su madre o institutriz. ${ }^{36}$

Otros de los referentes del movimiento fueron los españoles Santiago Ramón y Cajal — ganador del premio Nobel de Medicina- y el endocrinólogo Gregorio Marañón, quienes ayudaban a apoyar las ideas de la validez del saber de la ciencia como formador de la personalidad del hombre moderno del futuro:

Tiempos vendrán en que la ciencia ilumine las conciencias y eleve los corazones.Y entonces, cuando desterrado el culpable fetichista del capital el hombre haya sido incorporado a las leyes de la evolución, cuando escudriñadas y explotadas las fuerzas naturales, el cosmos trabaje para nosotros, poniendo en acción infinitas máquinas y fabricando mercancías a precios irrisorios [...] cuando el ocio bien ganado permita la universalización de la ciencia y el arte, y todos puedan saborear las inefables armonías y bellezas que palpitan en el fondo de la naturaleza; cuando, en fin, redimidos por la solidaridad y el amor, todos nos sintamos ondas de una misma corriente vital, células hermanas de un mismo cuerpo... ¿qué significado tendrán las palabras rico y pobre, señor y esclavo, feliz y desdichado? ${ }^{37}$

Por su parte, Marañón hacía referencia a cómo el sistema nervioso era atacado con estímulos en la ciudad moderna, y en esas circunstancias la higiene personal debía ayudar a que los sujetos buscaran el debido descanso. El español afirmaba: "En la mayor parte de los pueblos civilizados la vida es tal que el sistema nervioso es inmoderadamente excitado. Hay personas que llevan una vida excesivamente apresurada, teniendo apenas tiempo para comer durante las horas de trabajo". ${ }^{38}$

35. "Psicología Integral: El ambiente pesimista", Tribuna Literaria (Santiago de Chile) 1 de noviembre de 1925: 4 .

36. La voz del metalúrgico (Santiago de Chile) 4 de octubre de 1940: s.p.

37. "La sociedad futura", Acción Directa (Santiago de Chile) agosto de 1924: s.p.

38. "Cartilla de Higiene Personal. Cuidado del Sistema Nervioso. Necesidad del descanso", La Hoja Sanitaria (Santiago de Chile) septiembre de 1926: s.p. 
Bajo un espíritu comunitario, el 11 de junio de 1923 con el médico Juan Gandulfo a la cabeza se inauguró un policlínico nocturno para atender las necesidades más sentidas del sector obrero, organizado por el Comité Sanitario de la International Workers of the Wolrd (I.W.W), en la que: "los obreros somos capaces de organizar nuestros servicios médicos sin la ayuda del Estado, ni de las instituciones filantrópicas, gracias a la iniciativa libre". ${ }^{39}$ Además, publican la llamada Hoja Sanitaria para tratar temas higiénicos físicos y mentales. Esta publicación se alimenta, en este último sentido, de las ideas de médicos tan relevantes como Richard Von Krafft-Eving y su obra Psychopathia Sexualis (1886) para decir que "El instinto sexual constituye una de las más importantes necesidades del organismo humano, pocos son los que saben comprender la poderosa influencia que la vida sexual ejerce en los sentimientos, en el pensamiento y sobre las acciones individuales y colectivas de la humanidad". ${ }^{40}$

Por su parte, las mujeres fueron un público específico para las estrategias discursivas de los anarquistas. A ellas se les manifestaba la necesidad de refundar una nueva relación con su sexualidad para levantar una "huelga de vientres":

De nuevo me dirijo a los pobres y les digo: NO OS CASEIS, NO PROCREEÍS, NO TENGAIS HIJOS. Echad triple botón o triple llave a vuestros marruecos. Haceos triple nudo gordiano a vuestro nervio viril. No os reproduzcáis. No perpetuéis vuestra miseria, vuestras enfermedades, vuestro aherrojamiento moral y material, vuestras lacras, vuestros estigmas de humanidad explotada, degenerada, minimizada. Sabotead el capitalismo negándole vuestros hijos. ${ }^{41}$

Para conseguir estos propósitos, los anarquistas metropolitanos manifestaban la necesidad de superar la anemia social que tenía al pueblo sin fuerzas, dormido por los efectos del sistema económico. Era una especie de "letargo criminal que ni la más fuerte alternativa, ni el más recio sacudón han logrado despertar de este sueño de marmotas". ${ }^{42}$ La fatiga y el cansancio producto de la explotación — a la que los médicos le llamaban surmenage - debía ser denunciada para cesar en sus funestos efectos. Para esto debían dejar de ser una masa informe de sujetos, dormida en la inconsciencia y el dolor. ${ }^{43}$

Por último, los anarquistas al igual que sus pares burgueses también plantearon su propio decálogo de vida. Promulgaron "reglas para vivir con salud", las que reforzaban aspectos higiénicos de la alimentación, postura física, horas de descanso, ejercicio, limpieza, vestimenta y, particularmente, higiene mental. Entonces, si la vida en la ciudad era velocidad y apremio, los trabajadores no debían apurar su marcha de vida. Era una recomendación dificil de llevar, pero necesaria de considerar. Dentro de estas doce máximas la última señalaba:

39. "La salud es vida", La Hoja Sanitaria (Santiago de Chile) julio de 1926: s.p.

40. La Hoja Sanitaria (Santiago de Chile) diciembre de 1924: s.p.

41. "La huelga de vientres", Acción Directa (Santiago de Chile) 1 de mayo de 1925: s.p.

42. "Anemia Social”, Acción Directa (Santiago de Chile) 2 de octubre de 1934: s.p.

43. Boletín de los trabajadores industriales del mundo (Santiago de Chile) abril 1920: s.p. 
Higiene mental: Es tal vez la más importante: 'No se aflija ni se apure'. Conserve su calma. Gobierne sus emociones, sino ellas le gobernarán a usted. 'Esté alegre'. 'Sea amable'. 'Sea independiente'. Siga los consejos de Emerson y trabaje con sus propias manos; sosténgase con sus pies y formule sus propios pensamientos. Así adquirirá el dominio de sí mismo, que es la característica del verdadero hombre. ${ }^{44}$

\subsection{La apropiación socialista de los saberes psicológicos: entre las pulsiones y los reflejos condicionados}

Si para los anarquistas la anemia social era uno de los principales vicios que había que combatir, para los socialistas el país era toda una "república de vagabundos" en la que la miseria provocaba que una serie de niños deambulara por las calles y se convirtieran en potenciales víctimas de los vicios y delitos. Del mismo modo que sus pares anarquistas, los socialistas se manifiestan a favor de una redefinición del rol de la mujer en términos de salud e higiene. En ese sentido, las mujeres y el deporte era una relación que debía ser estrechamente establecida. Así, el diario obrero El Sindicalista publicó una nota en 1935 que apelaba —y ofrecía al mismo tiempo- la participación de las compañeras en el Club Deportivo. El ejercicio fisico para el autor de la columna era uno de los principales factores de salud que complementaba a la alimentación y al sueño. La metáfora del motor humano se hacía presente:

Si la alimentación nos produce las suficientes calorías para mantener con vida nuestro motor humano, son los ejercicios sistemáticos los que eliminan por medio de la transpiración la escoria, los venenos, que poco a poco se acumulan dentro de nuestro cuerpo; además, los ejercicios nos hacen fortalecer los pulmones, endurecer los músculos, hay un equilibramiento del sistema nervioso [...] es por eso la imprescindible necesidad que todas Uds., debéis practicar el deporte, sea cual fuera. ${ }^{45}$

Las exigencias de la vida cotidiana, el trabajo mental que se exigía debido a la multiplicidad de estímulos que empapan los sentidos de los sujetos era una cuestión de la cual comenzar a preocuparse. Entonces, la vida cotidiana debía ser un espacio de disputa por los hábitos de todos — en este caso de las mujeres - las que conviven en

oficinas mal ventiladas, los talleres con sus ruidos producidos por las maquinarias, las tiendas con ese movimiento permanente del público, etc., han contribuido a un porcentaje enorme de enfermedades nerviosas y otros trastornos en general. Especialmente el sexo femenino es víctima de grandes males: la neurastenia, histeria, tuberculosis y anemia, avanzan con pasos agigantados siendo un peligro constante para $\mathrm{Uds} .^{46}$

44. La Hoja Sanitaria (Santiago de Chile) enero de 1926: s.p.

45. "A mis compañeras", El Sindicalista (Santiago de Chile) 1 de septiembre de 1935: s.p.

46. "A mis compañeras", El Sindicalista (Santiago de Chile) 1 de septiembre de 1935: s.p. 
Por otro lado, si la ciencia cultivaba al ser humano, el arte también generaba bienestar a quienes lo consumían con lo que se provocaba una "liberación emotiva”. Esta era la función social del arte, que los socialistas querían impulsar entre sus correligionarios. La opresión del sistema capitalista también podía tener una salida estética para las almas sufrientes que podían lograr una homeostasis interna. ${ }^{47}$ Por lo tanto, la oferta que los diarios obreros hacen a sus lectores era introducirlos en una retórica de autogestión de sí mismos para alcanzar los mejores resultados para la lucha personal y política:

LA REEDUCACIÓN - El sistema pedagógico de la reeducación es uno de los frutos que ha dado a la humanidad el desarrollo de la Psicología Experimental y que permite a los adultos, en cualquiera edad, reanudar el período escolar para poder así repasar sus conocimientos y estar siempre al día y en esta forma marchar siempre al unísono con el progreso y no quedarse atrás, pues, es muy cierto ese proverbio que dice: renovarse o morir, pues la estagnación es la muerte..$^{48}$

Conciencia y voluntad eran los factores más importantes que se planteaban para conseguir el desarrollo humano. La introspección era la herramienta mental más poderosa en este sentido, ya que era vista como el método para tomar contacto con el "Yo interior". Las patologías de la personalidad eran consideradas por los postulados del psicólogo francés Théodule Ribot, quien con su ayuda comenzaba a hacerse presente la idea de inconsciencia: "Referente a la mente la ciencia médica tiene pruebas incontrarrestables de cuyas funciones simultáneas se desarrollan unas de otras independientemente, eso si que alrededor de ciertas ideaciones particulares, y muchas veces estas actividades quedan fuera del control de la conciencia y llegan a producir perturbaciones graves". ${ }^{49}$

En este sentido, lo inconsciente - o mentalidad subconsciente si se respeta su descendencia francesa- comenzó a ser visto como una fuente importante de información para la vida de los sujetos. Se lo presentaba como un aspecto misterioso del "sí mismo", que debía ser descubierto si se sabe que "Contestando esto desde el punto de vista científico y al mismo tiempo de acuerdo con los conocimientos biológicos, veremos que la mentalidad sub-consciente puede ser la 'suma' o reunión coordinada de las pequeñas 'psiquis' o mentes de cada célula constitutiva del cuerpo". ${ }^{50}$ La voluntad, desde esta óptica, estaba en conflicto con aspectos desconocidos que provenían del subconsciente. Específicamente, la acción de la psicoterapia era explicada de la siguiente manera:

47. "Función social del arte", El Despertar Tranviario (Santiago de Chile) primera quincena de octubre de 1940: s.p.

48. "Auto-cultura Integral”, El Despertar Tranviario (Santiago de Chile) primera quincena de enero de 1941: s.p.

49. “Auto-cultura Integral”, El Despertar Tranviario (Santiago de Chile) segunda quincena de marzo de 1941: s.p.

50. “Auto-cultura integral: anomalías de la personalidad”, El Despertar Tranviario (Santiago de Chile) primera quincena de abril de 1941: s.p. 
La Psicoterapia. Dije anteriormente que la mente dentro de sus actividades regula y controla en forma automática el funcionamiento de los órganos que corresponden a la digestión, a los de la circulación sanguínea, como también al de la respiración y al de la vida celular. Pues bien, se crea en la mente un conjunto de ideas organizadas con todas sus modalidades y con su potencia propia, creando un concepto de 'evidencia-energía' en forma que vaya a la restauración de la salud, no es errado pensar que la mente en esta forma obrará directamente bajo su influjo afectando en esta forma a los órganos enfermos o a los tejidos en tal forma que los beneficia procediendo al restablecimiento de sus funciones. ${ }^{51}$

De esta manera, los socialistas están preocupados por difundir con cierta densidad la idea de que la mente humana es una importante fuente de riqueza y ansiedades simultáneamente. Los socialistas — tal como lo habían hecho los anarquistas algunos años antes - proclamaban que la fuerza del capitalismo radicaba en su capacidad para adormecer o hipnotizar — apoyado por el fascismo - a los trabajadores hasta llegar a convertirlos en una masa informe e influenciable de sujetos. Por eso, era tan importante la autoformación en estas materias:

Pero en realidad, el agente más seguro para hipnotización en su aspecto general es la SUGESTIÓN; ya sea obrando directamente en la mente de otra persona por medio de órdenes y de conceptos adecuados a este caso. Estando ya en este estado de receptibilidad, se produce la fascinación que provoca la desconexión poligonal; esto es: la mente subconsciente no obedece ya al "centro psíquico superior", y que según el Dr. Grasset, "es el centro delYo personal consciente y responsable". ${ }^{52}$

La real liberación de los sujetos estaba condicionada a su despertar de la consciencia que disipara los efectos impresos a la humanidad por la religión. ${ }^{53} \mathrm{La}$ superstición y el pensamiento infantil son denunciados por los socialistas como los rudimentos neuróticos de estas formaciones culturales. Estos serán reemplazados, una vez que los obreros se apoderen de los medios de producción, por sentimientos de seguridad económica. En este sentido, Sigmund Freud es citado para estos fines como alguien que ayudó a develar este engaño, pero con serias limitaciones, ya que tampoco psicologizarán un conflicto que es material:

La escuela del psicoanálisis señala otros individuos en la génesis de la religión. Hace ver que en muchas religiones bien desarrolladas, la principal deidad es llamada 'el padre' y deduce de éste, así como de otros muchos datos, la conclusión de que las creencias religiosas son, en su raíz, una generalización hecha por los adultos, de la actitud de los niños hacia sus padres. Sugiere que el

51. "Auto-cultura integral", El Despertar Tranviario (Santiago de Chile) primera quincena de junio de 1941: s.p.

52. "Auto-cultura integral: el sueño hipnótico", El Despertar Tranviario (Santiago de Chile) primera quincena de abril de 1941: s.p.

53. "Pueblo y religión", El Despertar Tranviario (Santiago de Chile) segunda quincena de mayo de 1941: s.p. 
sentimiento de desamparo, la necesidad de propiciación, el miedo, la necesidad de amar y evocar el amor, con creencias religiosas, está en completo desacuerdo con el criterio de los socialistas. ${ }^{54}$

Si de afectos infantiles se trataba, la sexualidad aparece como un campo lleno de reflexiones para los socialistas, quienes ven en la educación sexual una herramienta importante para el crecimiento responsable de la sociedad. Desean disputar este campo a los sectores conservadores mediante el reconocimiento de la naturaleza instintiva del ser humano y, por ende, la pertinencia de una educación universal de estos aspectos. El doctor Luis Lara Pardo respondía en cuanto a la relevancia de la educación sexual:

Mucho más eficaz es lo que los psicoanalistas llaman la 'sublimación' de los impulsos: consiste en proporcionar al individuo derivativos útiles, agradables y sanos que lo libren de la "obsesión sexual". Nadie ignora que el celibato forzoso, cuando no tiene derivativo eficaz, suele conducir a la perversión o a la neurosis. La higiene fisica que debe aplicarse a todo el cuerpo, y a todos los órganos sin excepción, y la higiene mental, que se dirige principalmente al carácter, y debe tratar las cuestiones sexuales, más bien indirecta que directamente, sin detenerse complacientemente en ellas, bastará para permitir que la mayoría de los futuros adultos pase por la existencia con un mínimo de consecuencias desastrosas..$^{55}$

Por lo tanto, la educación era el recurso terapéutico en el que la sublimación se constituía en un elemento dinámico de la psique para reconducir sus impulsos y satisfacerlos gracias al logro de productos socialmente valorados como el arte, el trabajo, el deporte, la producción intelectual, entre otros. Los vicios como el alcoholismo eran vistos desde una perspectiva transgeneracional ${ }^{56}$ y condenados también al interior del movimiento obrero, ya que le quitaba fuerza a la organización y, finalmente, al desarrollo del país. El vicioso era visto como un lastre social que no estaba a la altura del progreso.

Por eso, en reiterados números se hacen llamados a luchar contra estos vicios a través de la psicoterapia con una clara raigambre oriental:

En la práctica de la cultura psíquica está el verdadero sendero que con toda seguridad conducirá a la persona a la perfección y a la realización de sus más grandes y bellos ideales. Esta nueva ciencia [...] tiene posibilidades aún insondables, libros valiosos hay que hablan en forma elocuente sobre esto, llevando algunos como título "Cultura mental", "Higiene psíquica", "Mentalismo científico", "Hata yoga" y "Raja yoga", etc. ${ }^{57}$

54. "Pueblo y religión", El Despertar Tranviario (Santiago de Chile) segunda quincena de mayo de 1941: s.p.

55. “¿Es necesaria la educación sexual?”, El Despertar Tranviario (Santiago de Chile) primera quincena de marzo de 1941: s.p.

56. "Maldito alcohol", El Despertar Tranviario (Santiago de Chile) segunda quincena de junio de 1941: s.p.

57. "La forma de tratar los vicios y las anomalías", El Despertar Tranviario (Santiago de Chile) segunda quincena de julio de 1941: s.p. 
Los sujetos debían cultivarse para lograr el dominio de sí mismos en términos físicos y mentales. La lectura de libros y folletos - en clave de autoayuda - era la manera de consumo que los socialistas veían como más viable para penetrar a la clase trabajadora. Más aún, se introduce la figura del "psiquiatra", quien — por ejemplo, en el caso del análisis de un caso de alcoholismo- "se adentra en su vida íntima y llega a conocer el desarrollo de su infancia, el ambiente en que vivió, su modo de hacer frente a los problemas de la vida, sus reacciones a los momentos desagradables". 58

Particularmente, el caso del alcoholismo ayuda a entender que el lenguaje psicoanalítico presente en estas declaraciones se combinaba con un tratamiento basado en la administración de premios y castigos inspirados en la psicología rusa:

El sistema de REFLEJOS CONDICIONADOS, a que me refiero, habrá de tener beneficiosos resultados, no sólo para los obreros tranviarios, ya que el ejemplo que significa para otros trabajadores no tardará en ponerse en práctica en otros gremios o industrias con el consiguiente mejoramiento de las condiciones generales de vida de quienes se sometan a él, sino también para la familia chilena y para la economía de nuestro país que verá, en forma, disminuido considerablemente el ausentismo al trabajo y demás consecuencias inherentes al alcoholismo. ${ }^{59}$

Desde esta perspectiva, Freud entregaba la retórica de mayor plasticidad de cambio en el ser humano y Pavlov — con su teoría de los reflejos condicionados y el cambio conductual- ofrecía un método aparentemente eficaz y sobre todo económico de administrar, teniendo a su haber buenos resultados. Es una especie de freudopavlovismo en el cual existía un sistema terapéutico que se concentraba en el alcoholismo como principal problemática, pero que, además, implicaba una formación integral que postulaba una serie de disciplinas que los trabajadores debían consumir: Filosofia de la Historia, Geografia Económica, Higiene Mental, Religiones Comparadas, Historia Literaria e Idiomas. En este sentido, si bien se reconoce un uso impreciso de estas fuentes teóricas, se destaca la búsqueda de reconciliación y compatibilidad con fines prácticos.

\subsection{Los comunistas y los saberes psi: educar a la masa para que no caiga en la hipnosis del fascismo}

Las publicaciones comunistas durante el periodo se mostraron menos receptivas a la presencia de ideas psicológicas. La estructura dramática de sus relatos siempre hizo referencia a la variable mental como unidad crítica de la desigualdad y lucha de clases. La vida en Rusia era proyectada como el gran ejemplo que los comunistas chilenos debían seguir para adquirir valores revolucionarios: "Viva al día. Adquiera

58. “¿A quién se les puede llamar alcohólicos?”, El Despertar Tranviario (Santiago de Chile) segunda quincena de mayo de 1944: s.p.

59. “¿A quién se les puede llamar alcohólicos?”, El Despertar Tranviario (Santiago de Chile) segunda quincena de mayo de 1944:s.p. 
convicciones y anhelos revolucionarios. Si Ud. ¡No se renueva moralmente, vegetará cual los guijarros del camino! Hay que responder a la época, al grado de evolución alcanzado.Viva al día, reciba la influencia de la revolución Rusa" . ${ }^{60}$ Bajo esta dirección, la apuesta se dirigía a la formación educativa y política de los adherentes con el propósito de generar una fortaleza de carácter para la lucha social:

Hay que inculcar en el cerebro del pueblo todo aquello que tienda a dignificar y embellecer la vida. El arte, la ciencia y todo lo que hasta hoy es fuente de sabiduría y belleza debe llegar hasta el pueblo para desviarlo de la rutina y abyección. Fuerza es que los que dirigen las multitudes posean una amplia cultura moral y sincera. Fracasarán todos aquellos que a fuerza de ignorantes son insinceros y viciosos. ${ }^{61}$

Para dirigir a las masas de trabajadores había que formar adecuadamente el carácter a través de una formación científica y artística. Seguramente, la primera tenía la ambición de que cuando los obreros se hicieran de las máquinas pudieran utilizarlas en favor del pueblo y, así, superar la manifiesta escasez. Las angustias de la clase trabajadora en relación con la explotación capitalista sobre el tiempo de trabajo se pueden percibir en la carta de Sofia Méndez publicada a modo de testimonio:

A las seis de la mañana estoy en pie y como no tengo tiempo para prepararme una taza de café es preciso que me vaya sin haber probado un bocado y así tengo que aguantarme hasta la hora de salida que es a las doce.Y después de almorzar, entrar a la una y media y salir a las 6. En todo ese tiempo que está en la fábrica se lo lleva una inclinada sobre unas cajas poniendo zapatos y más zapatos con el ojo del patrón encima, avizorante. Si descansa una un momento, gruñe como un perro y amenaza con ponerla de patitas en la calle. A veces no puedo contener mis ansias de retarlo, de injuriarlo y lo haría, aunque me dejase sin trabajo, si no fuera por nuestra madre vieja y casi inválida, ¡Pobre mi vieja!, ¿qué haría sin mí? ${ }^{62}$

Dependencia económica, extensas horas de trabajo de pie, cansancio y frustración marcaban la publicación. Más adelante, en 1936 se celebrará con una semblanza la muerte de Ivan Pavlov — fallecido el 27 de febrero de ese año- en la cual se consignaba:

El puño levantado con que Pavlov aparece en la fotografia que publicamos es ilustrativo del cambio que se operó en el ilustre hombre de ciencia del viraje del mundo íntegro científico e intelectual del pueblo soviético ante el socialismo. Al morir Pavlov, era uno de los más entusiastas defensores del Estado Proletario. Pavlov, como otros sabios, intelectuales y artistas, descubrió que la revolución había abierto las puertas a un progreso sin trabas. Los recursos íntegros del Estado proletario eran suyos. ${ }^{63}$

La muerte de Pavlov sirvió como estrategia para consagrar las relaciones entre la ciencia y la revolución. La idealización del científico y del progreso soviético

60. El Comunista (Santiago de Chile) 6 de agosto de 1921: s.p.

61. El Comunista (Santiago de Chile) 3 de septiembre de 1921:s.p.

62. Sofia Méndez, "Carta”, El Comunista (Santiago de Chile) 17 de mayo de 1921: s.p.

63. "Ha muerto Pavlov", Bandera Roja (Santiago de Chile) mayo de 1936: s.p. 
seguían reforzando la idea de que los hombres cultos son los encargados de encabezar los grandes cambios sociales. Al igual que los anarquistas y socialistas, los comunistas denunciaron el efecto hipnótico que el capitalismo provoca unido al fascismo. Para eso la clase trabajadora debía estar atenta a la histeria —usada como sinónimo de hipnotismo y sugestión - que provocaba, por ejemplo, el nazismo:

Nuestro pueblo chileno a demostrado ser un pueblo vigoroso, íntegro y viril y no permitirá que la demagogia fascista nacista o fascistizante lo castre de su dignidad humana. Al oscurantismo y al sentimiento histérico de los nacistas oponemos la capacidad de pensar, de razonar y de usar libremente nuestra inteligencia que son los elementos indispensables de un pueblo libre y culto. ${ }^{64}$

La histeria era contagiosa para los comunistas, ya que consideraban que las masas pueden caer bajo el influjo hipnótico de los discursos totalitarios a causa de la miseria en la que viven. De este modo, la verdadera resistencia era la de estar firmes y conscientes para desmontar este engaño. En efecto, el trabajo político consistía en educar a las agrupaciones de personas para que pudieran politizarse.

En resumidas cuentas, los comunistas buscaban politizar para que los sujetos fueran conscientes de sus derechos sociales y así ganarle en privilegios a la burguesía. El uso de esta metáfora refleja el llamado a "despertar" una consciencia de clase, lo que implicaba entender las limitaciones concretas ante la ausencia del poder sobre los medios de producción. Desde este punto de vista, la lucha se jugaba en el terreno mental de la clase obrera, la que activamente, gracias al cultivo de su inteligencia para descubrir las artimañas del capitalismo y el fascismo, configuraba una verdadera barrera sanitaria - higiénico mental si se desea mencionar asíque facilitaría el advenimiento de un nuevo sujeto social.

\section{Conclusiones}

Karl Marx al referirse a la jornada laboral capitalista declaraba lo siguiente: "El capital es trabajo muerto que sólo se reanima, a la manera de un vampiro, al chupar trabajo vivo, y que vive tanto más cuanto más trabajo vivo chupa. El tiempo durante el cual trabaja el obrero es el tiempo durante el cual el capitalista consume la fuerza del trabajo que ha adquirido". ${ }^{65}$ Es así como expresaba una de las importantes alegorías sobre las condiciones de vida que la clase trabajadora enfrenta en el sistema capitalista. Como se pudo ver, el robo de las energías físicas y psíquicas fue un argumento perfectamente reconocible en los diarios obreros de Santiago de Chile a comienzos del siglo XX. En este sentido, recientemente se retoma esta idea de la obra de Marx desde una lucha de clases por el sentido común de los sujetos, que se traducía en una disputa por las representaciones del mundo circundante y los objetos del consumo que trataba de encontrar una resistencia activa a

64. Bandera Roja (Santiago de Chile) 2 de julio de 1936: s.p.

65. Karl Marx, El capital, t. 1, vol. 1 (México: Siglo XXI Editores, 2008) 279-280. 
la enajenación fetichista del capital. ${ }^{66} \mathrm{El}$ asecho psicológico del sistema burgués a la clase trabajadora ya había sido advertido por autores como, por ejemplo, Wilhelm Reich ${ }^{67}$ - lo que costó su expulsión del psicoanálisis ortodoxo en 1934—, ${ }^{68}$ quien denunciaba cómo la fuerza pulsional sexual era ahogada moralmente, lo que garantizaba la presencia de neurosis. ${ }^{69}$ Por lo tanto, la política revolucionaria debía tener en consideración cómo el capital ahoga a los sujetos convirtiéndolos en una masa informe, desclasada y, por ende, manipulable. La psicología, en consecuencia, es vista como una herramienta que según el costado social en el que se encuentre puede servir para que - como ideología - la clase popular sea dominada mediante el control social, la implantación de estereotipos y valores acordes con el sistema político y económico burgués. ${ }^{70}$

Bajo este marco de discusión, las fuentes históricas mostraron cómo en Santiago de Chile tanto anarquistas y socialistas como los comunistas buscaron en los saberes psicológicos — con una particular visión de la higiene mental - manipular "el espíritu" — alma o psique, dependiendo de la retórica usada - con el fin de dar sustento individual y social a sus respectivos proyectos políticos. Se detectó que, tal como lo hicieron los médicos y otros personeros del Estado, los obreros tenían una visión positiva sobre el uso de estos saberes, se resistían a los usos más abusivos y alejaban de una representación pasiva de sí mismos. De esta forma, ellos creían que estaban protagonizando también una lucha psicológica a la par de una disputa por las condiciones materiales de existencia en las que destacaban su capacidad agencial. Usando las categorías analíticas de la psicología, denunciaron con firme convicción que la burguesía buscaba "hipnotizar" a la clase trabajadora, sumirla en una especie de anemia social al modo del vampiro mencionado por Marx. Por lo tanto, la misión era la de "despertar a la consciencia" a sus correligionarios, instruyéndolos en los principios del funcionamiento mental, la fuerza de los instintos y el papel de la educación para lograr derrocar al sistema económico explotador. También se encargaron de redefinir los parámetros de la sexualidad "normal" — atrapada bajo la influencia de la religión, principalmente - y sensibilizaron a los suyos para difundir la educación sexual, un nuevo rol de la mujer y el embarazo controlado. Con todo esto, se pudo ver su capacidad como sujetos con un saber particular, empapados de una actividad que los aleja de las tradicionales visiones como "objetos" de la psicología tradicional. En este sentido, la colaboración social como resistencia al uso hegemónico de la psicología pensada desde su instrumentación opresiva, la

66. Jorge Veraza Urtuzuástegui, Marx y la psicología social del sentido común. (Contribución a una teoría marxista del sentido común) (México: Editorial Itaca, 2018) 9-54.

67. Wilhelm Reich, Materialismo dialéctico y psicoanálisis (México: Siglo XXI Editores, 1970) 178-191.

68. Mary Higgins y Chester Raphael, eds., Reich Speaks of Freud.Wilhelm Reich Discusses His Work and His Relationship with Sigmund Freud (Nueva York: Farrar, Strauss, and Giroux, 1967) 255-260.

69. Wilhelm Reich, La revolución sexual (Buenos Aires: Diable Érotique, 1984) 13-40.

70. Ian Parker, La psicología como ideología. Contra la disciplina (Madrid: Catarata, 2010) 51-78; David Pavón-Cuéllar, Psicología crítica. Definiciones, antecedentes, historia y actualidad (México: Editorial Itaca, 2019) 7-14. 
que los calificaba recurrentemente de degenerados, viciosos y vagos, fue puesta entre paréntesis para ser usada a favor de sus ideas políticas y proyectos de sociedad y ser humano. No es a la psicologización en sí misma — porque los diarios muestran que entran en esos códigos-, sino a los efectos enajenantes de su uso.

Finalmente, este recorrido permitió profundizar en una ruta alternativa para la historiografía iberoamericana de los saberes psicológicos, la que regularmente ha ignorado la participación de este grupo social por alejarse de los tradicionales retratos del científico regularmente constituido. Este enfoque historiográfico cuestiona, además, la posición ética desde la cual se mira el pasado, sus protagonistas y las acciones que llevan a cabo. Una historia con inspiración antropológica se hace necesaria para recuperar las voces de los "nativos" en vez de infantilizarlos como malos ejemplos de una lectura equivocada de la ciencia psicológica. Queda en el futuro seguir profundizando en esta dirección y demostrar la capacidad agencial del pueblo para detectar, comprender y solucionar sus propios problemas psicológicos.

\section{Fuentes}

\section{Periódicos}

Acción Directa (Santiago de Chile) 1921, 1922, 1924, 1925, 1934.

Agitación (Santiago de Chile) 1925.

Bandera Roja (Santiago de Chile) 1936.

Boletín de los trabajadores industriales del mundo (Santiago de Chile) 1920.

El Comunista (Santiago de Chile) 1921.

El Despertar Tranviario (Santiago de Chile) 1940, 1941, 1944.

El Sindicalista (Santiago de Chile) 1935.

La Hoja Sanitaria (Santiago de Chile) 1924, 1926.

La voz del metalúrgico (Santiago de Chile) 1940.

Tribuna Libertaria (Santiago de Chile) 1923-1925.

\section{Bibliografía}

Aránguiz Pinto, Santiago. "Rusia roja de los soviets: recepción de las Revolución Rusa, del bolcheviquismo y de la cultura política en el mundo obrero revolucionario chileno (1917-1927)". Tesis de doctorado en Historia, Pontificia Universidad Católica de Chile, 2012.

Campos Marín, Ricardo. Alcoholismo, medicina y sociedad en España (1876-1923). Madrid: Consejo Superior de Investigaciones Científicas, 1997.

. "De la higiene del aislamiento a la higiene de la libertad. La reforma de la institución manicomial en Francia (1860-1940)". Frenia. Revista de Historia de la Psiquiatría 1.1 (2001): 37 -64.

. "La psiquiatría en la ciudad. Higiene mental y asistencia psiquiátrica extramanicomial en España en la década de 1920”. Frenia. Revista de 
Historia de la Psiquiatría 4.1 (2004): 101-111.

Correa, María José y Mauro Vallejo. Cuando la hipnosis cruzó los Andes. Magnetizadores y taumaturgos entre Buenos Aires y Santiago (1880-1920). Santiago de Chile: Pólvora Editorial, 2019.

Dagfal, Alejandro. "El pasaje de la higiene mental a la salud mental en la Argentina, 1920-1960. El caso de Enrique Pichon-Rivière”. Trashumante. Revista Americana de Historia Social 5 (2015): 10-36. Doi: 10.17533/udea.trahs.n5a02

Damousi, Joy y Mariano Ben Plotkin. Eds. The Transnational Unconscious. Essays in the History of Psychoanalysis and Transnationalism. Londres: Palgrave Macmillan, 2009.

DeVos, Jan. Psychologisation in Times of Globalisation. Nueva York: Routledge, 2012. DeShazo, Peter. Trabajadores urbanos y sindicatos en Chile: 1902-1927. Santiago de Chile: Centro de Investigaciones Diego Barros Arana de la Dirección de Bibliotecas, Archivos y Museos, 2007.

Devés Valdés, Eduardo. “La circulación de las ideas económico-sociales de Latinoamérica y el Caribe, en Asia y África ¿cómo llegaron y cómo se diseminaron? (1965-1985)". Universum. Revista de Humanidades y Ciencias Sociales 23.2 (2008): 86-111.

Fuentes, Miguel, "Entre el nacimiento de la clase obrera en Chile y su constitución como sujeto político. El ‘Congreso Obrero’ de 1885 y la Huelga general de 1890 como antecedentes históricos de la matanza de Santa María”. Cuadernos de Historia Marxista 1.1 (2009): 1-19.

Foucault, Michel. La vida de los hombres infames. Ensayos sobre desviación y dominación. La Plata: Altamira, 2006.

Fuster Sánchez, Nicolás. El cuerpo como máquina. La medicalización de la fuerza de trabajo en Chile. Santiago de Chile: CEIBO Ediciones, 2013.

Gherovici, Patricia y Christopher Christian. Eds. Psychoanalysis in the Barrios. Race, Class, and the Unconscious. Londres: Routledge, 2019.

Girón, Álvaro. "Kropotkin between Lamarck and Darwin: the impossible synthesis". Asclepio. Revista de Historia de la Medicina y de la Ciencia 55.1 (2003): 189-213. Doi: 10.3989/asclepio.2003.v55.i1.94.

Heelas, Paul y Andrew Lock. Indigenous Psychologies. The Anthropology of the Self. Londres / Nueva York: Academic Press, 1981.

Higgins, Mary y Chester Raphael. Eds. Reich Speaks of Freud. Wilhelm Reich Discusses His Work and His Relationship with Sigmund Freud. Nueva York: Farrar, Strauss, and Giroux, 1967.

Hobsbawm, Eric. A la zaga. Decadencia y fracaso de las vanguardias del siglo XX. Barcelona: Crítica, 1999.

Huertas, Rafael. "El papel de la higiene mental en los primeros intentos de transformación de la asistencia psiquiátrica en España”. Dynamis 15 (1995): 193-209.

. Historia cultural de la psiquiatría. Madrid: Catarata, 2012.

Illanes, María Angélica. "En el nombre del Pueblo, del Estado y de la Ciencia, (...)”. 
Historia de la salud pública. Chile (1880-1973). Hacia una historia social del siglo XX. Santiago de Chile: Ministerio de Salud, 2010.

Illouz, Eva. La salvación del alma moderna. Terapia, emociones y la cultura de la autoayuda. Madrid: Katz Editores, 2010.

Lázaro, Mario y Manuel Cortés. Anarquismo y lucha antialcohólica en la Guerra Civil Española (1936-1939). Madrid: Papel Piedra, 2005.

Lobato, Mirta Zaida. La prensa obrera. Buenos Aires: Edhasa, 2009.

Marx, Karl. El capital. Tomo 1.Volumen 1. México: Siglo XXI Editores, 2008.

Mülberger, Annette. Los límites de la ciencia, espiritismo, hipnotismo y el estudio de los fenómenos paranormales (1850-1930). Madrid: Consejo Superior de Investigaciones Científicas, 2016.

Parker, Ian. La psicología como ideología. Contra la disciplina. Madrid: Catarata, 2010.

Pavón-Cuéllar, David. Psicología crítica. Definiciones, antecedentes, historia y actualidad. México: Editorial Itaca, 2019.

Reich, Wilhelm. La revolución sexual. Buenos Aires: Diable Érotique, 1984. . Materialismo dialéctico y psicoanálisis. México: Siglo XXI Editores, 1970.

Rieff, Philip. The Triumph the Therapeutic. Uses of Faith after Freud. Wilmington: ISI Books, 2006.

Ríos Molina, Andrés. Cómo prevenir la locura. Psiquiatría e higiene mental en México, 1934-1950. México: Siglo XXI Editores, 2016.

Rose, Nikolas. La invención del sí mismo. Poder, ética y subjetivación. Santiago de Chile: Pólvora Editorial, 2019.

Ruperthuz Honorato, Mariano. Freud y los chilenos. Santiago: Pólvora Editorial, 2016.

Thompson, E. P. La formación de la clase obrera en Inglaterra. Madrid: Capitán Swing, 2012.

Thomson, Mathew. "Mental hygiene as an international movement". International Health Organisations and Movements, 1918-1939. Ed. Paul Weindling. Cambridge: Cambridge University Press, 1995.

Turkle, Sherry. Psychoanalytic Politics. Jacques Lacan and Freud's French Revolution. Nueva York: The Guilford Press, 1992.

Venancio, Ana Teresa y Cristina Facchinetti. "Historiografias: de la psiquiatría en Brasil y sus instituciones”. Revista Argentina de Psiquiatría 27 (2016): 177-187.

Veraza Urtuzuástegui, Jorge. Marx y la psicología social del sentido común. (Contribución a una teoría marxista del sentido común). México: Editorial Itaca, 2018.

Vetö, Silvana. "Higiene mental infantil y psicoanálisis en la Clínica de la Conducta, Santiago de Chile, 1936-1938”. Asclepio. Revista de Historia de la Medicina y de la Ciencia 69.2 (2017): 1-17. Doi: 10.3989/asclepio.2017.18.

Salazar, Gabriel. La historia desde abajo y desde adentro. Santiago de Chile:Taurus, 2017. 